\title{
Three Layer Macro Network Constraint Based Precision Planning of Middle Voltage Distribution Networks
}

\author{
Wang Jingyu ${ }^{1, ~ *, ~ W a n g ~ Z h u d i n g ~}{ }^{1,2}$, Zhang Yongbin ${ }^{3}$, Zhai Jinqian ${ }^{4}$, Tan Xiao ${ }^{2}$ \\ ${ }^{1}$ Chongqing Star Electrical Company, Chongqing, China \\ ${ }^{2}$ State Key Laboratory of Power Transmission Equipment \& System Security and New Technology, Chongqing University, Chongqing, \\ China \\ ${ }^{3}$ State Grid Henan Electric Power Company, Zhengzhou, China \\ ${ }^{4}$ State Grid Zhenzhou Electric Power Company, Zhengzhou, China
}

Email address:

3567377@qq.com (Wang Jingyu),348402467@qq.com (Wang Zhuding), zyb6362@163.com (Zhang Yongbin), jinqianzhai@163.com (Zhai Jinqian),38118932@qq.com (Tan Xiao)

${ }^{*}$ Corresponding author

\section{To cite this article:}

Wang Jingyu, Wang Zhuding, Zhang Yongbin, Zhai Jinqian, Tan Xiao. Three Layer Macro Network Constraint Based Precision Planning of Middle Voltage Distribution Networks. Science Discovery. Vol. 6, No. 2, 2018, pp. 72-84. doi: 10.11648/j.sd.20180602.11

Received: March 31, 2018; Accepted: May 15, 2018; Published: June 22, 2018

\begin{abstract}
Refined planning has become the key to improve the efficiency of power grid enterprises under the background of new electricity reform.Thus, a complete set of ideas and methods are proposed for the precise planning of medium voltage distribution networks based on three layer macro networks, in this paper. The three layer macro networks consist of channel networking, mesh networking and transformer networking, which reflect the top level determination of overall planninand and overall coordinationg of networking. The channel networking definites all substation locations and optimizes inter station channel layout, in order to ensure the land resource reservation. Mesh networking optimizates the mesh partition based on the principles of nearest tie connection and load clustering, strengthening the partition determinacy. Transformer networking optimizates the tie connection of transformers as a whole based on the tradeoff between equipment utilization enhancement and connection simplicity. Based on the constraints of three layer macro networks and power supply area classification, the grid connection mode and construction\&reconstruction standards are selected according to different classification, and the medium voltage distribution network is finally obtained through the transformation from global planninh to the local planning inside each mesh. The proposed method is compatible with the existing related guidelines, and shows a specific landing program for the planning ideas of overall planning in space, near far combination in time and clear right and responsibility in administration, with the scientific and accurate of planning being comprehensively enhanced. The method also has the reference value for the revision and refinement of relevant guidelines to some a degree. It is shown through real diatribution network planning that the proposed ideas and methods are effective and applicable.
\end{abstract}

Keywords: Middle Voltage Distribution Network Planning, Three Layer Macro Networking Constraints, Mesh Definition, Mesh Partition Optimization, Precise Planning

\section{基于三层宏观组网约束的中压配网精准规划}

\author{
王敬宇 ${ }^{* *}$, 王主丁 ${ }^{1,2}$, 张永斌 ${ }^{3}$, 翟进乾 ${ }^{4}$, 谭笑 ${ }^{2}$ \\ ${ }^{1}$ 重庆星能电气有限公司, 重庆, 中国 \\ 2输配电装备及系统安全与新技术国家重点实验室, 重庆大学, 重庆, 中国 \\ 3 国网河南省电力公司, 郑州, 中国 \\ ${ }^{4}$ 国网郑州供电公司, 郑州, 中国
}




\section{邮箱}

3567377@qq. com (王敬宇), 348402467@qq. com(王主丁), zyb6362@163.com(张永斌), jinqianzhai@163.com(翟进乾), 38118932@qq. com (谭笑)

摘要: 新电改背景下, 精细化规划成为提高电网企业效益的关键, 本文为此提出了一套完整的基于三层宏观组网约束 的中压配网精准规划方法。三层宏观组网分为通道组网、网格组网和主变组网，以体现全局统筹的顶层决定性和网架 的整体协调性。通道组网明确全局的站址和站间通道的优化布局, 确保土地资源预留; 网格组网基于就近联络和负荷 聚类原则, 实现网格成片优化划分, 并强化了网格划分的确定性; 主变组网基于设备利用率提升和接线简洁的权衡, 实现了主变联络结构的全局优化。基于三层宏观组网和供区分类约束，分类优选网格接线模式和一、二次建设改造标 准, 将复杂的全局馈线规划转化为各网格内馈线规划。提出的方法在兼容相关导则基础上, 针对空间上全局统筹、时 间上远近结合和管理上权责明确的中压配网规划理念找到了具体的落地方案, 全面提升了规划的科学性和精准性, 对 相关导则修编和细化有一定的参考价值。实际应用表明了本文方法的实用和有效。

关键词: 中压配电网规划, 三层宏观组网约束, 网格定义, 网格划分优化, 精准规划

\section{1. 引言}

新电改背景下, 精准规划成为优化资源配置, 避免投 资浪费, 提升电网企业效益和社会效益的重要龙头。与主 网不同，配网项目体量大，建设、运维、营销和调度等多 部门协调管理困难，涉及业扩、居配、迁改和通道等复杂 建设环境, 往往导致规划和建设项目两层皮, 项目落地困 难。

目前, 配电网存在的主要问题有: 线路交叉迂回供电, 联络关系复杂, 发生故障不易查找; 设备负载不均衡, 重 载、轻载和不满足 N-1设备相对集中出现在负荷密度较大 地区, 迎峰度夏压力大; 间隔管理不到位, 如间隔用尽变 电站仍轻载。这些问题导致配电网指标不佳, 如联络率与 可转供率等关键指标均低于导则要求, 配电网架提升空间 很大。

针对配网存在的问题, 在实际配网规划建设中, 通常 强调“问题为导向”的思路, 但由于缺乏目标导向理论上存 在无穷解, 无法确保规划方案的全局合理性和长效性, 容 易造成投资浪费。

近年来, 越来越多的供电企业开展了基于供电网格的 配电网精准规划与研究 [1], 以期解决中压线路线路接线繁 杂问题并明确建设运维调度权限。

现有配电网网格划分有两种思路: 一是基于控规地块 功能定位、开发深度或可靠性要求划分[2] [5], 属于传统 的分区划分方法, 随意性较大, 随意性大, 或忽视了电气 设备 (如变电站和中压馈线) 布局优劣对网格供电可靠性 和经济性的影响; 二是基于若干组标准接线的供电能力大 小和范围划分网格[6 11], 即按负荷大小定量或准定量划 分方法, 但由于标准接线的供电范围没有具体明确的划分 方法, 不同规划人员可能得到完全不同的结果但由于 [9 13]。其中, 文献[5] 结合工程实践研究了网格化供电 模式, 提出了网格之间以变电站定向联络为主干, 网格内 部以线路分段之间联络为依托的“联络组合”理念，应用于 复杂城市配电网建设造中。文献[7]通过网格化规划将配电 网供电区域按区块划分为供电网格, 将复杂无序的中压配 电网化繁为简, 以供电网格为基本单元开展规划并构建目 标网架, 提出了各类网格的过渡改造原则和网格管理思路。
但是当前两种网格划分方法存在的最大的问题是：思 路缺乏整个规划区域各网格供电范围的相互协调, 没有在 全局统筹基础上体现“技术上可行、经济上最优”的规划理 念, 难于获得网格划分的优化方案, 造成不应有的浪费。 在满足现有相关导则要求下, 本文提出了基于三层宏观组 网的中压配网精准规划方法。通过空间上的全局统筹, 可 得到基于设施布局的站间通道组网、基于就近联络优化的 网格成片组网和基于设备利用率优化的主变全局组网, 并 以此为约束强化规划结果的顶层决定性和整体协调性; 通 过时间上的远近结合强化规划的目标导向和利旧原则; 通 过管理上的权责明确, 提升规划方案的可操作性。实际应 用表明, 提出的方法全面提升了规划的科学性和精准性。

\section{2. 基本概念和总体思路}

\section{1. 基本概念}

（1）变电站优化规划

在负荷分布已知的情况下, 以变电站带负荷能力和供 电半径为约束条件, 以变电站和中压线路投资费用和运行 费用最小为目标, 确定变电站的位置、容量和供电范围 [15]。

(2) 通道组网

通道组网主要优化和描绘整个规划区域内变电站站 间的通道联络结构, 用于协调通道资源、规避建设风险。

(3) 网格组网

网格组网基于就近联络和负荷聚类原则, 在全局范围 内优化网格划分, 形成以变电站为枢纽的网孔型负荷分区 组网结构。

(4) 主变组网

主变组网基于全局设备利用率提升和接线简洁的权 衡, 优化各主变间的联络馈线条数或联络结构。

(5) 网架过渡

目标网架和过渡网架应基于三层宏观组网进行协调 规划。为减少规划的言目性、重复性和投资浪费, 电网建 
设改造应以远景年的理想网架为目标 (即目标导向), 并 充分利用现有设备, 尽量延长设备生命周期 (即利旧原则)。

\section{（6）权责分明}

规划管理必须将责任落实到人, 高中层领导主导三层 宏观组网, 基层部门依据宏观组网构建各网格目标网架和 过渡网架。

\section{2. 总思路}

如图1所示, 现有中压配网规划的主要内容及总体流 程类似, 主要包括现状分析、负荷预测、变电站规划、网 架规划、项目编制、方案评估和投资决策等。本文方法研 究的重点为空间上基于全局统筹的三层宏观组网, 时间上 基于“近”的利旧原则和“远”的目标导向; 管理上基于组网 结构的权责明确。

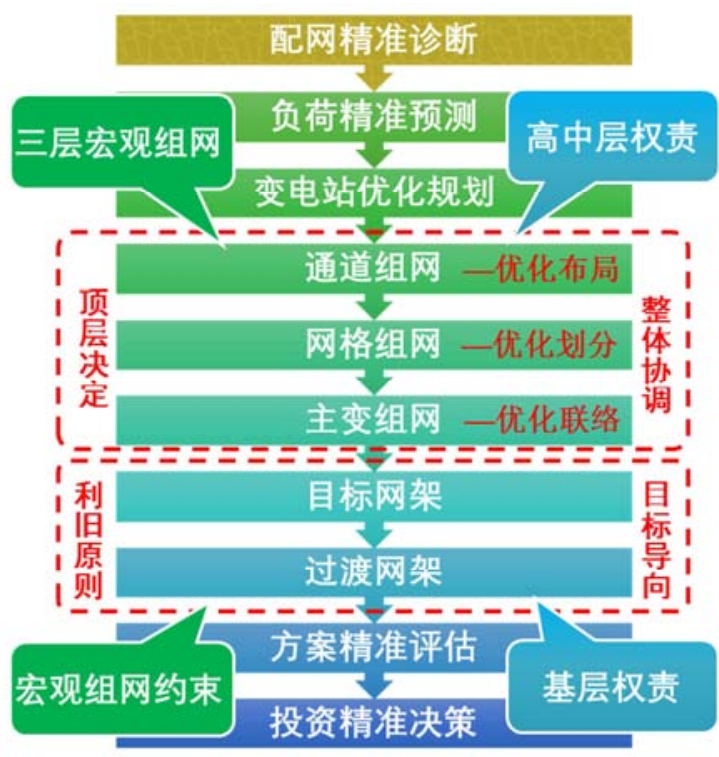

图1 基于三层宏观组网约束的中压配网精准规划流程。

\section{3. 三层宏观组网的全局统筹}

三层宏观组网包括通道组网、网格组网和主变组网, 体现了全局组网的顶层决定性和网架的整体关联性。

\section{1. 通道组网}

依据现状线路及通道、规划路网、负荷分布、远景变 电站布点和变电站供电半径等因素, 明确全局的站址及其 联络通道布局, 确保土地资源预留, 规避建设风险。通道 组网构建思路如图2所示。

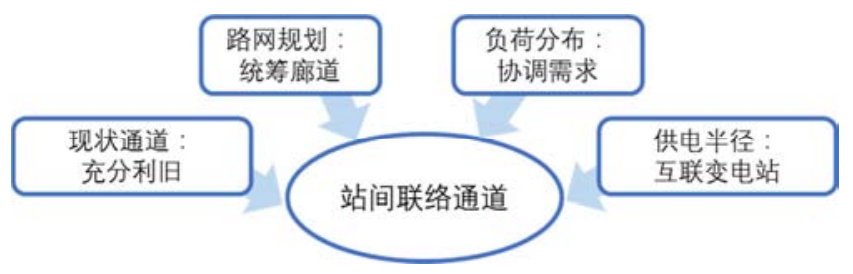

图2 通道组网的构建思路。

受区域地域特点、负荷密度和电力通道等影响, 变电 站布点和中压线路走向通常会呈现一定规律特征, 通道组 网的基本结构可抽象为狭长型、环状型、棋盘型和不规则 型等若干种, 如图3所示（图中黑点为变电站）。

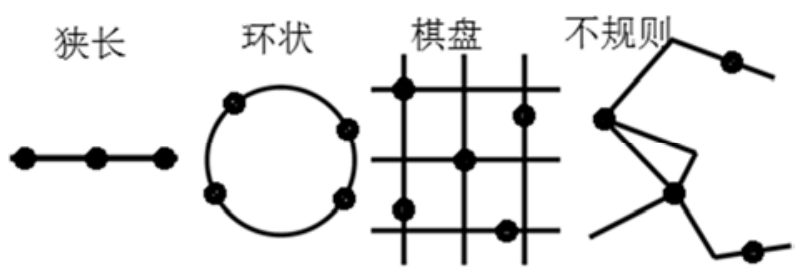

图3 通道组网的典型结构。

根据实际规划区情况, 通道组网可能会由多个简化结 构组合而成。

\section{2. 网格组网}

网格组网在全局范围内优化网格的划分, 强化了网格 划分的科学性和唯一性。

\subsection{1. 网格定义和编码}

本文定义网格为以变电站为枢纽的负荷大小适中的 网孔型分区, 分区内部主供和联络变电站 (不分主备) 相 同或负荷位置相对集中, 各分区间相对独立（原则上不相 互联络）。

为便于管理, 网格编码应唯一和容易识别, 如图4所示。

YN YX HT ZX TS A 01

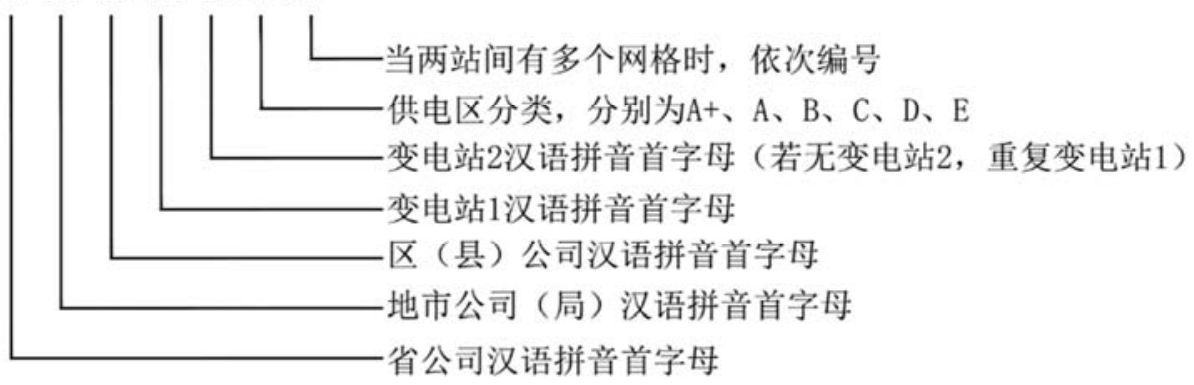

图4网格编码示意图。 


\subsection{2. 网格组网方法}

网格组网是在全局范围内优化和协调网格的供电范 围划分。

（1）确定各负荷主供站

由变电站优化规划获得的供电范围, 确定每个负荷或 地块的主供变电站。

（2）确定各负荷备供站

在考虑供电半径约束条件下, 就近确定各负荷可能存 在的备供站（即联络变电站）, 有条件时应综合考虑主干 道路、山川、河流和供电分区等地理因素对供电路径远近 的影响。

（3）先将主供站和备供站都相同的负荷划分为一个 供区, 再将主供站和备供站相反的两个供区划分为一个站 间联络网格。

（4）对于那些不能归入站间联络网格的负荷, 分别 在每个变电站供电范围内, 采用负荷聚类方法形成站内联 络 (或辐射型接线) 网格。
(5) 网格细分

对于网格过大的情况, 为了避免形成过多线路相互联 络的复杂网络, 网格应结合各标准接线的典型供电能力

(如单环网8MW, 双环网16-20MW、三供一备为 $24 \mathrm{MW}$ 等) 进一步细分, 以期各网格最终负荷接近推荐值 $32 \mathrm{MW}$

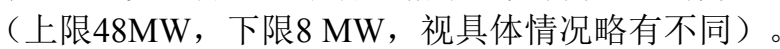

需要指出的是, 网格过小 (比如相互联络的两回线) 会限制采用具有较大供电能力的多分段多联络和主备馈 线等接线模式, 不适合通道资源紧张或电网改造较为困难 的地区。

\subsection{3. 组网链图}

网格组网可由网格链图表示, 图中需明确变电站站址、 联络链及其线路回路数, 以及网格的供电范围 (或边界), 如图5所示。

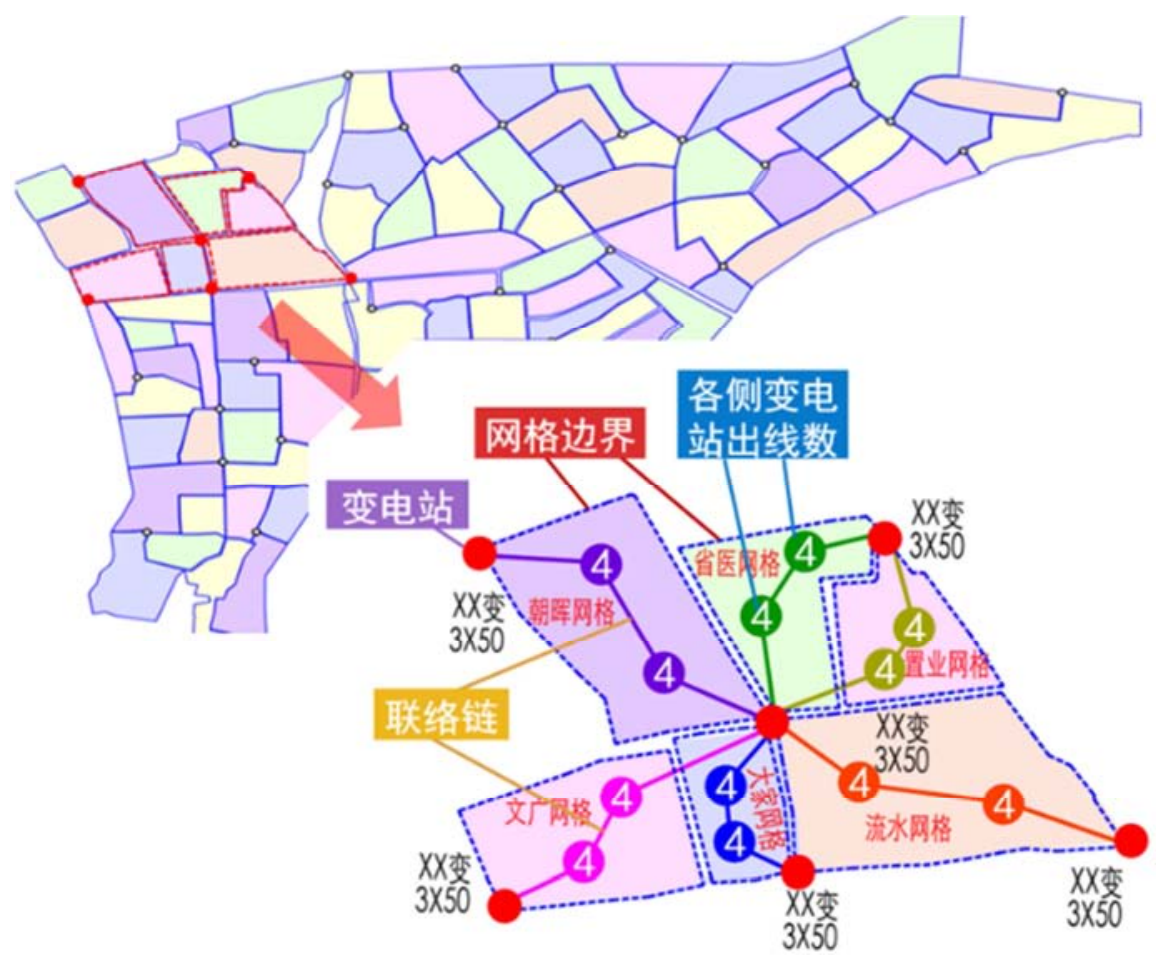

图5 网格链示意图。

\subsection{4. 网格组网优势}

(1) 全局最优

基于负荷就近联络和负荷聚类原则, 网格组网或划分 方法科学规范, 结果趋于全局最优: 经济、可靠、唯一、 差异和精准。

（2）供电可靠

尽量实现网格内部多电源、互倒互供, 保证供电可靠 性。

(3) 网架简洁

网格间相对独立, 避免形成过多线路相互联络的复杂 网络（即蜘蛛网）。

\section{3. 主变组网}

基于成片组网原则, 间隔调配优化各主变间的联络馈 线条数或联络结构, 在兼顾接线简洁的基础上实现设备利 用率的全面优化。

\subsection{1. 优化依据}

依据相关导则 [16 18], 不同类型地区推荐的变电站主 变台数、主变容量及常用主变推荐的出线间隔数量如表 1 和表2所示。 
表1 不同类型地区变电站建设规模。

\begin{tabular}{lll}
\hline 供电区域类型 & 台数（台） & 单台容量（MVA） \\
\hline A+、A类 & $3 \sim 4$ & $63 、 50$ \\
B类 & $2 \sim 3$ & $63 、 50 、 40$ \\
C类 & $2 \sim 3$ & $50 、 40 、 31.5$ \\
D类 & $2 \sim 3$ & $40 、 31.5 、 20$ \\
E类 & $1 \sim 2$ & $20 、 12.5 、 6.3$ \\
\hline
\end{tabular}

表2 不同主变容量的 $10 \mathrm{kV}$ 出线规模。

\begin{tabular}{llllll}
\hline 主变容量(MVA) & $\mathbf{6 3}$ & $\mathbf{5 0}$ & $\mathbf{4 0}$ & $\mathbf{3 1 . 5}$ & $\mathbf{2 0}$ \\
\hline 推荐间隔数(个) & $12 \sim 16$ & $12 \sim 16$ & $8 \sim 12$ & $8 \sim 12$ & $6 \sim 8$ \\
\hline
\end{tabular}

基于导则中主变安全负载率(两主变 $65 \%$, 三主变 $87 \%$, 四主变 $100 \%$ ), 以及单主变最大负载率按 $80 \%$ 为重载考虑, 并依据导则推荐的导线选型及其载流量[17-19], 可计算得 到不同线路的允许的最大负载率，结果如表3所示。

表3 基于主变安全负载率的线路最大负载率。

\begin{tabular}{|c|c|c|c|c|c|c|c|c|c|}
\hline \multirow{2}{*}{ 容量（MVA） } & \multirow{2}{*}{$\begin{array}{l}\text { 线路 } \\
\text { 条数 }\end{array}$} & \multicolumn{2}{|l|}{ 单主变 (\%) } & \multicolumn{2}{|l|}{ 双主变 $(\%)$} & \multirow[b]{2}{*}{ JKLYJ-185 } & \multirow[b]{2}{*}{ YJV22-3×300 } & \multirow{2}{*}{$\begin{array}{l}\text { 三主变 (\%) } \\
\text { YJV22-3×300 }\end{array}$} & \multirow{2}{*}{$\begin{array}{l}\text { 四主变 (\%) } \\
\text { YJV22-3×400 }\end{array}$} \\
\hline & & JKLYJ-120 & JKLYJ-150 & JKLYJ-120 & JKLYJ-150 & & & & \\
\hline \multirow{2}{*}{20} & 6 & 41.52 & 36.32 & 33.8 & 29.5 & -- & -- & -- & -- \\
\hline & 8 & 31.2 & 27.2 & 25.3 & 22.1 & -- & -- & -- & -- \\
\hline \multirow{2}{*}{31.5} & 8 & 49.12 & 42.88 & 39.9 & 34.8 & 30.2 & -- & -- & -- \\
\hline & 12 & 32.72 & 28.56 & 26.6 & 23.2 & 20.1 & -- & -- & -- \\
\hline \multirow{2}{*}{40} & 8 & -- & -- & -- & -- & 38.3 & 31.4 & 42.1 & 45.7 \\
\hline & 12 & -- & -- & -- & -- & 25.6 & 21.0 & 28.1 & 30.5 \\
\hline \multirow{2}{*}{50} & 12 & -- & -- & -- & -- & 31.9 & 26.2 & 35.1 & 38.1 \\
\hline & 16 & -- & -- & -- & -- & 24.0 & 19.6 & 26.3 & 28.6 \\
\hline \multirow{2}{*}{63} & 12 & -- & -- & -- & -- & 40.3 & 33.0 & 44.2 & 48.0 \\
\hline & 16 & -- & -- & -- & -- & 30.2 & 24.8 & 33.1 & 36.0 \\
\hline
\end{tabular}

由该表可见, 与主变安全负载率对应的线路负载率近 似为 $40 \%$ 左右的经济负载率 $[14]$ 。因此, 在走廊通道资源 充足的前提下, 宜尽量推广结构简单、运维便捷和改造便 利的架空单联络、电缆单环网或双环网接线; 对于通道资 源紧张或电网改造较为困难的地区, 可依据实际需要选择 多分段多联络和主备馈线等结构较为复杂的接线模式, 以 提升线路的利用率。

\subsection{2. 安全负载率分析}

主变N-1时其最大安全负载率可按下式计算。

$$
\eta=\frac{n_{0}}{n_{0}+n_{1}} * 100 \%
$$

式中, $\eta$ 表示变电站最大安全负载率; $\mathrm{n}_{0}$ 表示变电站 正常出线数; $n_{1}$ 表示其他主变停运后需要由本主变增供的 线路数。

由式 (1) 可得到不同主变容量不同出线规模满足主 变N-1校验的主变最大负载率, 结果如表4所示。

表4 不同联络线条数与主变安全负载率。

\begin{tabular}{|c|c|c|c|c|c|}
\hline \multirow{2}{*}{ 容量(MVA) } & \multirow{2}{*}{ 出线(条) } & \multicolumn{4}{|c|}{ 主变负载率 $(\%)$} \\
\hline & & 1条 & 2条 & 3条 & 4条 \\
\hline \multirow{2}{*}{20} & 6 & 85.71 & 75.00 & 66.67 & -- \\
\hline & 8 & 88.89 & 80.00 & 72.73 & 66.67 \\
\hline \multirow{2}{*}{31.5} & 8 & 88.89 & 80.00 & 72.73 & 66.67 \\
\hline & 12 & 92.31 & 85.71 & 80.00 & 75.00 \\
\hline \multirow{2}{*}{40} & 8 & 88.89 & 80.00 & 72.73 & 66.67 \\
\hline & 12 & 92.31 & 85.71 & 80.00 & 75.00 \\
\hline \multirow{2}{*}{50} & 12 & 92.31 & 85.71 & 80.00 & 75.00 \\
\hline & 16 & 94.12 & 88.89 & 84.21 & 80.00 \\
\hline \multirow{2}{*}{63} & 12 & 92.31 & 85.71 & 80.00 & 75.00 \\
\hline & 16 & 94.12 & 88.89 & 84.21 & 80.00 \\
\hline
\end{tabular}

由上表可见，两主变间联络线路条数越少，主变N-1 时正常主变增供线路条数也就越少, 主变最大安全负载率 越高; 同时安全负载率也随出线规模的增加而提高。

特别要注意的是, 当两主变间联络线路数为 1 时, 变 电站负载率可提升至 $85.7 \%$ 94.2\%, 其中较大容量主变 $(40$ 、 $50 、 63 \mathrm{MVA}$ ) 可达 $92.3 \% \sim 94.2 \%$; 当两主变间联络线路回 数为 2 时, 变电站负载率可提升至 $75 \% \sim 88.9 \%$, 其中较大 容量主变可达 $85.7 \%$ 88.9\%。

\subsection{3. 主变间最佳联络数}

对于主变间只连 1 回的组网方式, 主变最大安全负载 率最高, 但与每一主变发生联络的主变数较多, 接线复杂, 而且对于负荷密度较低的区域或电网发展过渡期间, 单主 变和两主变站较多且变电站分布较为分散, 难以按两主变 间只连1回组网。

对于主变间连2回的组网方式, 较大容量主变的最大 安全负载率为 $85.7 \%$ 88.9\%, 接近三主变站安全负载率 $87 \%$ 。

对于主变间连 3 回或 4 回的组网方式, 主变最大安全负 载率偏低, 低于相关导则中三主变站安全负载率 $87 \%[11,16]$ 的规定, 主变设备利用率不高。

基于上述分析，兼顾接线简洁和设备利用率，本文推 荐主变间成片组网的简单规则: 异站主变间以仅连2回为 主的方式组网, 对于因通道紧张而出线困难的情况, 也可 连1回来提高主变设备利用率。对于某变电站与周边六座、 四座、三座和两座变电站发生联络的典型情况, 主变间成 片组网或联络方式如图6所示（图中不同颜色的圆点代表 不同主变, 不同颜色实线代表相应颜色主变供电的线路)。 

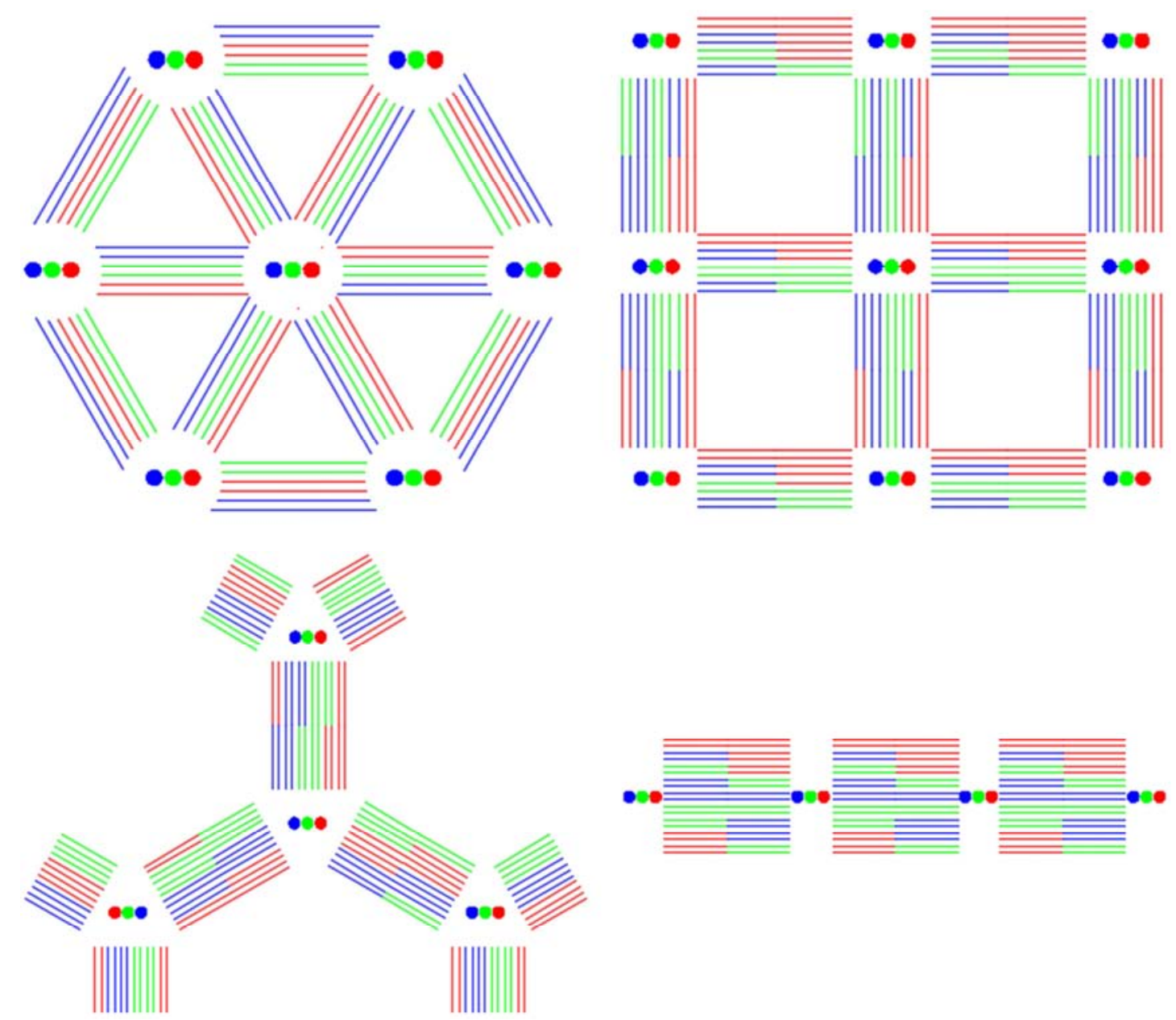

图6 主变组网典型接线方式示意图。

值得注意的是, 现有导则中主变最大负载率一般是指: 首先, 仅在站内转移负荷的情况下, 主变负载率不超过 $130 \%$; 然后，在短时（2小时）内将主变过载负荷进行站 间转移或切除。该导则存在的问题是: 没有提出进行短时 过载负荷站间转移的具体方案; 对于最大负载率 $100 \%$ 的 四主变站, 难于接纳相邻变电站短时过载的负荷, 影响系 统整体 $\mathrm{N}-1$ 。

推荐的简单规则既能兼容和完善现有导则, 又能适应 电网的发展:

首先, 是简单规则的兼容性: 较大容量主变 (即 40 、 50 和63MVA）的安全负载率可提升至 $85.7 \% \sim 88.9 \%$, 满足 现有导则两主变 $65 \%$ 和三主变 $87 \%$ 的要求。

然后，是简单规则对现有导则完善：i）提供了如何 进行短时过载负荷站间转移的优化解决方案; ii) 对于新 增落点困难的负荷集中区或4主变站, 也可考虑采用两主 变间仅连一回的方式组网, 使主变在超过 $90 \%$ 负载率时仍 满足N-1安全校验。

最后, 是简单规则的适应性, 随着站间负荷转移自动 化水平的提高, 简单规则可使中压配网对上级配网形成了 强有力支撑： i）对于任何主变台数的变电站, 较大容量 主变 $\mathrm{N}-1$ 的安全负载率可提升至 $85.7 \%$ 88.9\%, 且不依赖
短时过载; ii）高压配网可以弱化以节省投资, 容载比有 望下降至1.3 1.5。

\section{4. 基于组网约束的目标网架}

基于三层宏观组网约束和分类建设标准, 本文将复杂 的全局目标网架的构建从全局范围转化为各相互独立的 网格分区范围, 最终形成全局中压配网目标网架。

\section{1. 三层宏观组网约束}

基于三层宏观组网的优化结果, 通道组网的站间联络 通道提供了主干线路布线的候选路径; 网格组网提供了各 种馈线组供电的优化范围和负荷大小; 主变组网提供了馈 线间隔调配的简单规则。

\section{2. 分类建设标准}

本文对 A+、A、B、C、D和E类等供电分区[18]的各 网格, 分别提出了规范化的一、二次建设改造的标准和运 维管理措施, 内容涉及线路接线模式、负荷控制、设备选 型、配电自动化建设和运维管理措施等多个方面, 特点如 表5所示。 
表5 建设标准分类。

\begin{tabular}{|c|c|c|c|c|c|c|}
\hline \multicolumn{2}{|c|}{ 建设标准类型 } & \multicolumn{2}{|l|}{ 供电区分类 } & \multirow{2}{*}{$\begin{array}{l}\text { 负荷（MW） } \\
32,16 ~ 48\end{array}$} & \multirow{2}{*}{$\begin{array}{l}\frac{\text { 接线模式 }}{\text { 双环网, 单环网 }}\end{array}$} & \multirow{2}{*}{$\begin{array}{l}\text { 可靠率目标(RS-3) } \\
\geq 99.999 \%\end{array}$} \\
\hline \multirow{3}{*}{ T1 } & I & & 一般地区 & & & \\
\hline & II & A+、A机B矢㤥 & 通道紧张 & $24, \quad 16 \sim 24$ & 两供一备, 三供一备 & $\geq 99.999 \%$ \\
\hline & III & & 大容量用户密集 & $32,8 \sim 48$ & 双回直供开闭所 & $\geq 99.999 \%$ \\
\hline $\mathrm{T} 2$ & & B类非核心 & & $32, \quad 16 \sim 48$ & 多分段适度联络, 重要用户满足原则要求 & $\geq 99.965 \%$ \\
\hline $\mathrm{T} 3$ & & \multicolumn{2}{|l|}{ C类及以下 } & 视情况而定 & 多分段适度联络、单辐射 & $\begin{array}{l}C \geq 99.897 \% \\
D>99828 \%\end{array}$ \\
\hline $\mathrm{T} 4$ & & \multicolumn{2}{|c|}{ 受用户影响无法优化 } & 视情况而定 & 视情况而定 & 视情况而定 \\
\hline
\end{tabular}

（1） $\mathrm{T} 1$ 类建设标准

$\mathrm{T} 1$ 类建设标准规范了可靠性要求较高地区的多种网 格构建方案, 可依据实际情况灵活选取和组合, 典型接线 如图7 9所示 (图中, “二遥”指遥测和遥信, “三遥”指遥 信、遥测和遥控; 洋红色背景表示三遥节点层, 绿色背景 为二遥节点层）。其中, 子类 $I$ 为典型推荐方案, 适用面 较广; 子类 II 适用于通道紧张地区; 子类III适用于独立的 大容量用户密集区。

(2) $\mathrm{T} 2$ 类建设标准
$\mathrm{T} 2$ 类建设标准规范了架空线为主的城区和郊区, 接线 以单联络为主, 当通道或间隔受限时可适度增加联络提高 线路最大允许负载率，典型接线如图10所示。

（3） T3类建设标准

$\mathrm{T} 3$ 类建设标准规范了农村地区, 典型接线如图11所示。

（4） T4类建设标准

T4类建设标准针对非规范化区域, 适用于受用户和通 道等因素影响无法改造的地区, 推荐改造方案主要是依据 现有电网的局部优化, 典型接线如图12所示。

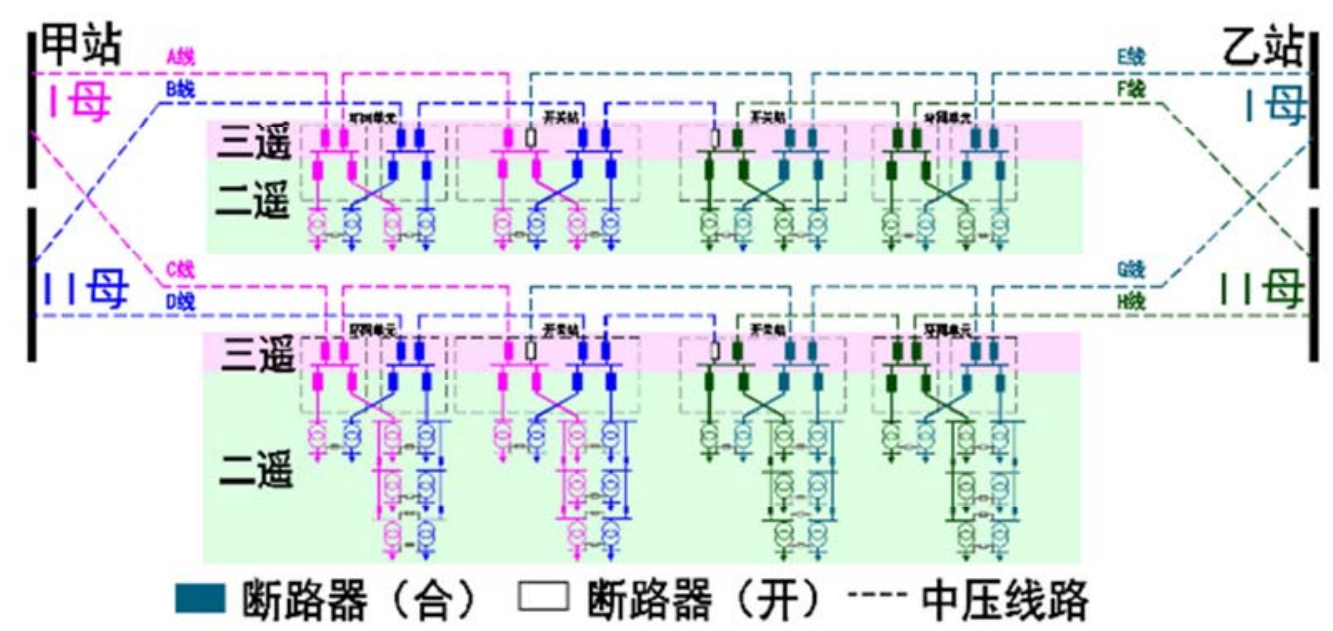

图7 T1（I ）建设标准推荐网架。

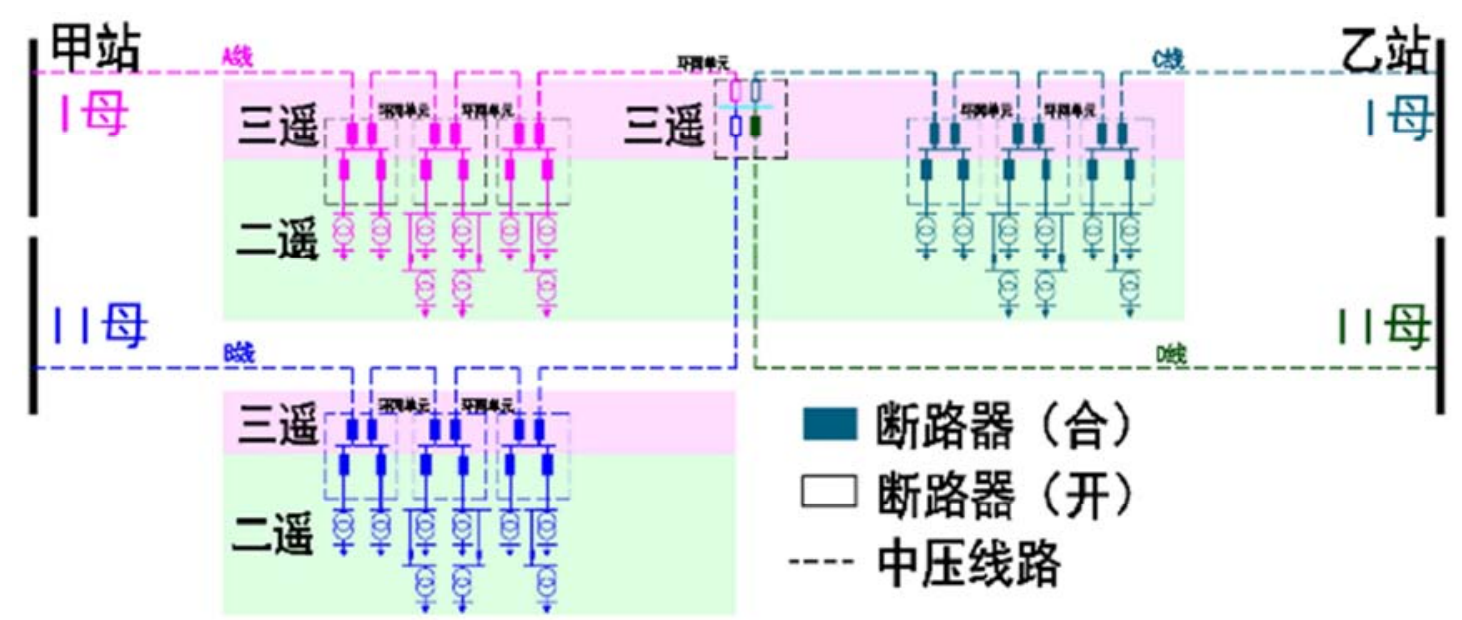

图8 T1（II）建设标准推荐网架。 


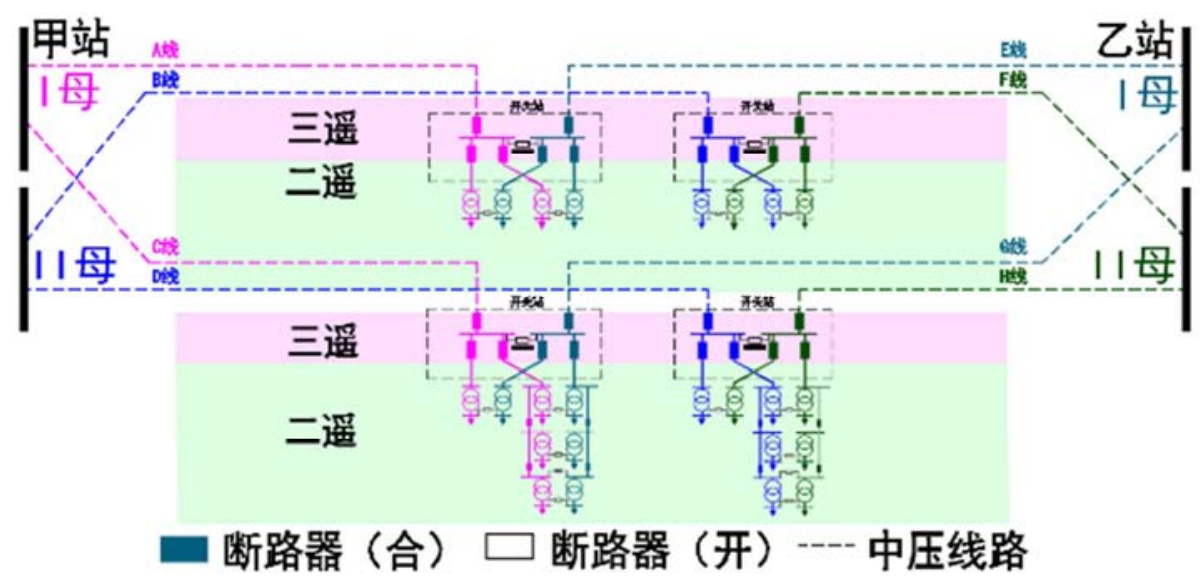

图9 T1（III）建设标准推荐网架。

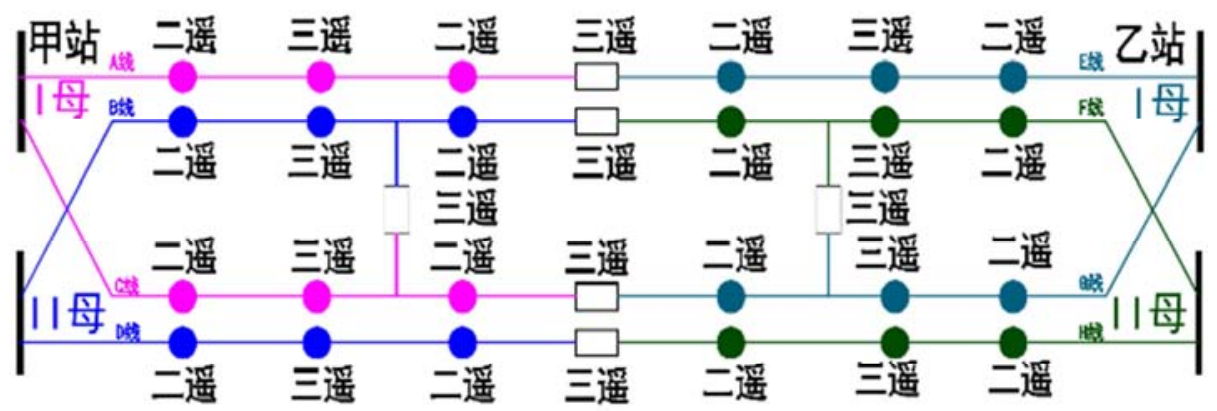

- 负荷开关（合） $\square$ 断路器（开）一中压线路

图10 T2建设标准推荐网架。
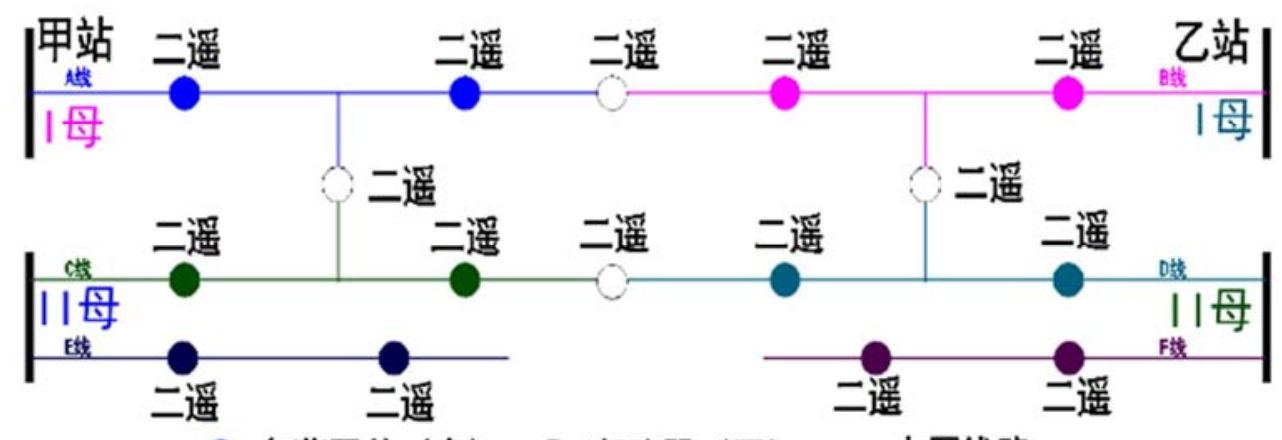

- 负荷开关 (合) 断路器 (开) 一中压线路

图11 T3建设标准推荐网架。
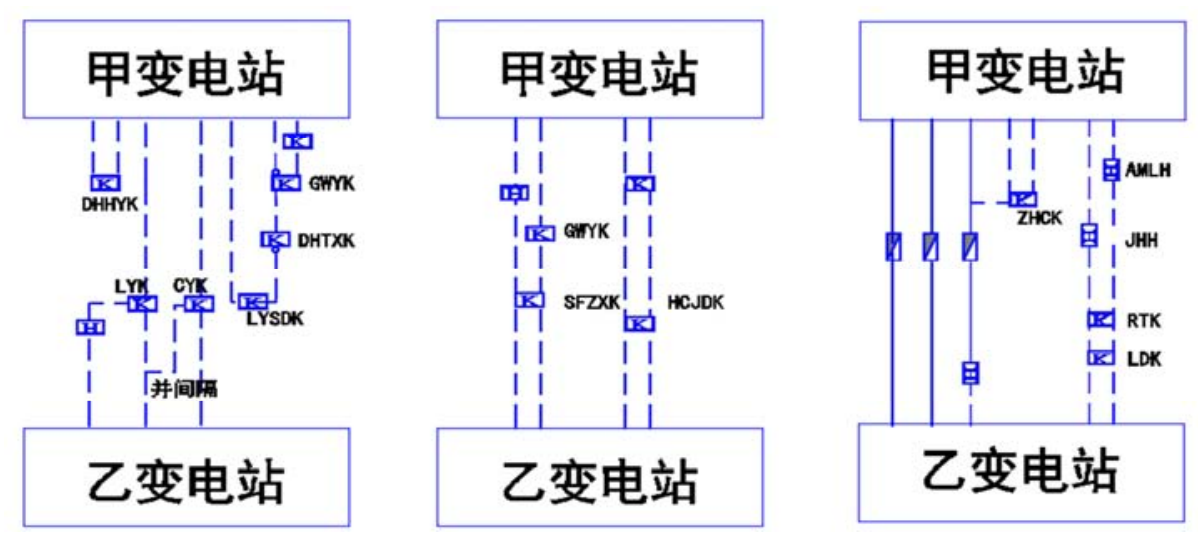

图12 T4建设标准推荐网架。 


\section{5. 网架的远近结合}

过渡年网架应与远景年目标相协调, 应充分考虑现有网 架, 结合市政和变电站建设时序, 抓住建设契机, 逐步优化。

\section{1. 新区}

按目标网架主干线构建, 做到“新建一片成型一片”。

（1）过渡年负荷与远景年接近的地区, 可参照远景 年组网模式, 一次性建成供电网格目标接线方式。

（2）过渡年负荷未成熟时，可减少网格内主供线路 条数, 也可多个网格采用串接或并接方式共享电源（如图 13所示），待新站投运后通过 $\pi$ 入或直接接入。

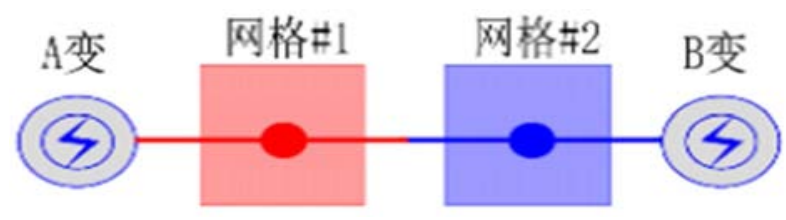

(a) 网格站间互联

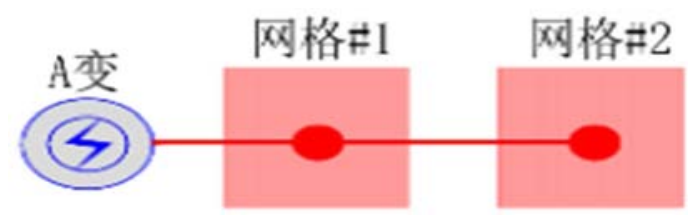

(b) 网格同站辐射

图13 过渡期网格合并示意图。

\section{2. 易改造地区}

不宜大规模改造，做到“改造一片完善一片”。

(1) 以变电站新建为契机, 成片改造网格并合理过 渡到目标网架。

（2）以中压线路新建为契机，调整主干、切改分支, 合理过渡到目标网架。

\section{3. 难改造地区}

采取“保持既有格局，局部理清关系”，适当调整主干 和分支及其联络方式。

\section{6. 规划管理的权责明确}

本文网架的规划管理涉及基于网格的信息化管理和 基于三层宏观组网的“权责明确”。

\section{1. 基于网格的信息化管理}

配网规划管理规范化和信息化方面, 将以配网网格 为基本单元, 结合生产系统、GIS系统、SCADA系统、 计量自动化系统、营销系统、项目系统和投资计划系统, 配合市政规划和通道资源等, 集成配网规划需要的数据, 有效掌握每个网格内设备数据、运行指标和负荷发展等 重要数据的的历史、现状和未来发展情况, 便于管理者 开展相关分析。进而以电网资源云平台为工具, 以数据 挖掘为支撑, 以可视化的地理图形展示为载体, 构筑基 于供电网格的配电网规划信息支撑平台。

\section{2. 基于三层组网的权责明确}

基于三层宏观组网的规划方法将管理责任分层分网 格落实到人, 有效明晰各层级规划人员的职责分工, 自上 而下传递理念, 自下而上提出需求, 不易出现管理真空或 交叉管理的问题, 强化了管理权限的刚性。

市局级领导主导通道组网, 把控电网整体布局, 通过 建立长效的企业政府沟通机制, 确保土地资源预留, 强化 了变电站站间联络通道布局刚性。

区县级领导依据通道组网, 主导网格组网和主变组网, 用成片组网思路全面优化网格划分和设备利用率, 强化了 电网联络结构刚性。

基层部门依据三层宏观组网, 基于丰富的运维管理经 验, 发挥熟悉现场实际的优势, 细化网格管理职责, 编制 建设改造项目, 确保项目落地, 强化了建设项目刚性。

\section{7. 实践应用}

本文方法已成功应用于多个省会城市。下面以Y市某 规划区域为例, 阐述基于三层宏观组网的中压配网精准规 划方法的具体应用。

\section{1. 通道组网的构建}

对于现状走廊通道建设情况较为成熟的区域, 应以利 用已有通道为主; 新增通道应充分考虑电力走廊的可行性, 主要考虑新投运变电站的出线, 但不得穿越区域内大运河 与铁路, 并尽量沿主干道分布。综合考虑现有通道、新增 通道、负荷分布和新增布点等四点因素, 形成如图14所示 的“三横三纵”的通道组网。 


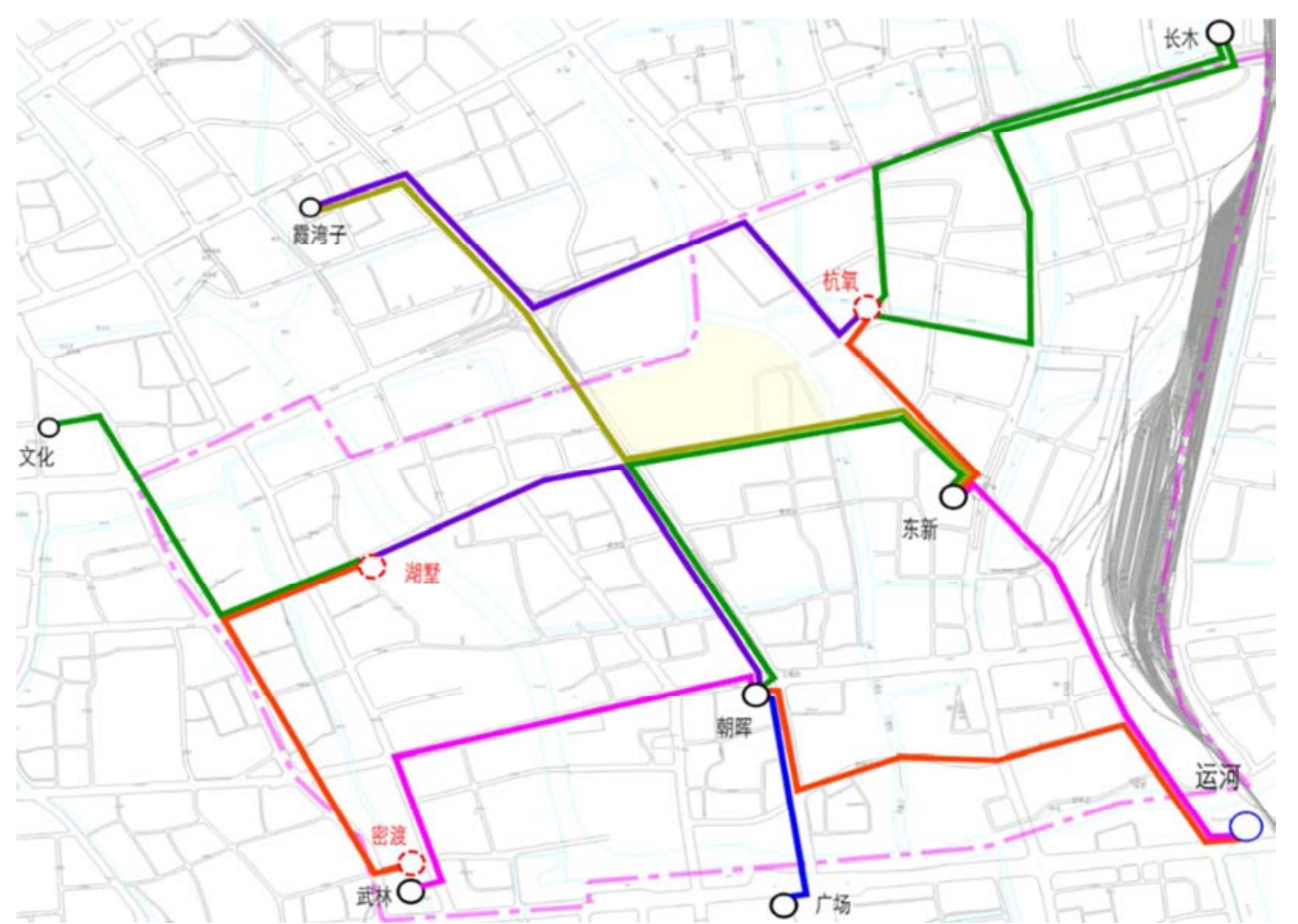

图14 规划区域站间联络通道示意图。

\section{2. 网格组网的构建}

基于空间负荷预测结果，开展变电站布点规划（略）：目标年规划区域共有区内 $110 \mathrm{kV}$ 变电站5座，区外 $110 \mathrm{kV}$ 变 电站5座。以通道组网为约束, 得到目标年如图15所示的网格链图, 共包含 12 个联络链。

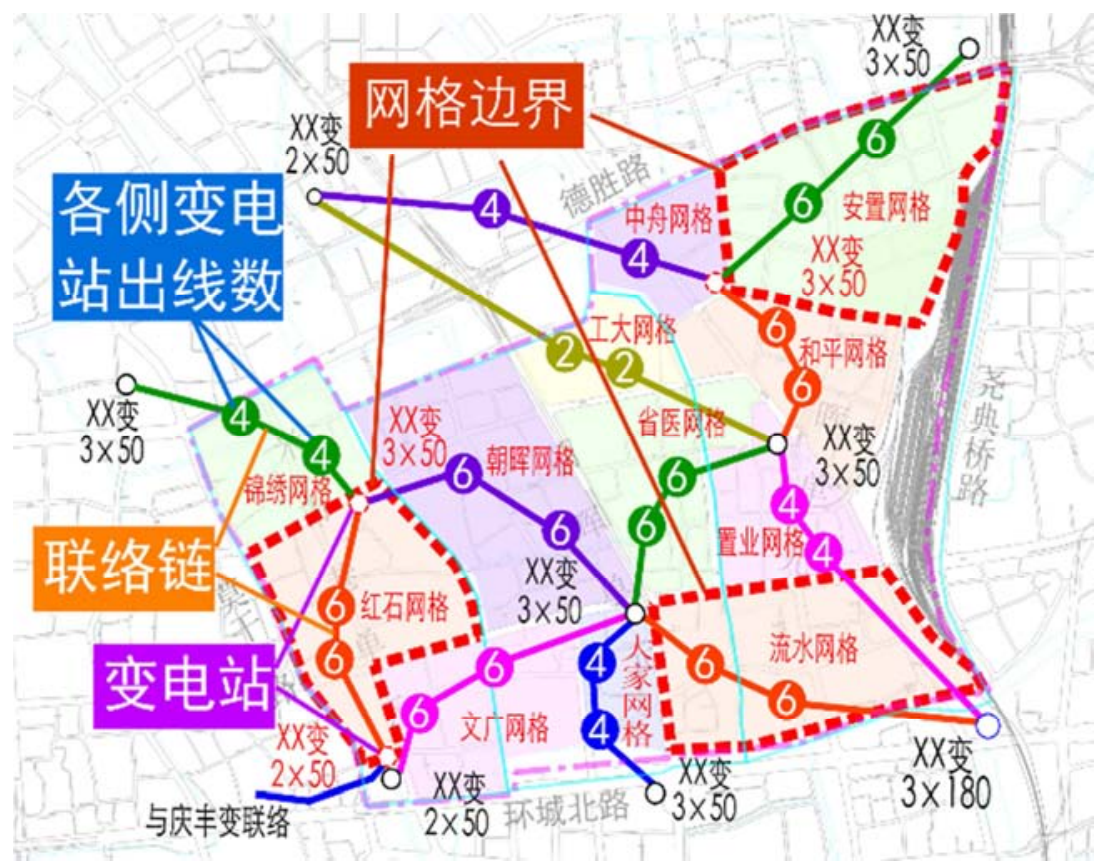

图15 规划区域目标年网格链。

\section{3. 主变组网约束}

依据本文推荐的主变间成片组网的简单规则和目标网架分类建设标准，规划区域主变组网方式采用异站主变间以 仅连2回的联络方式（如图16所示），相应的目标网架采用表4中的T1（I）建设标准。 


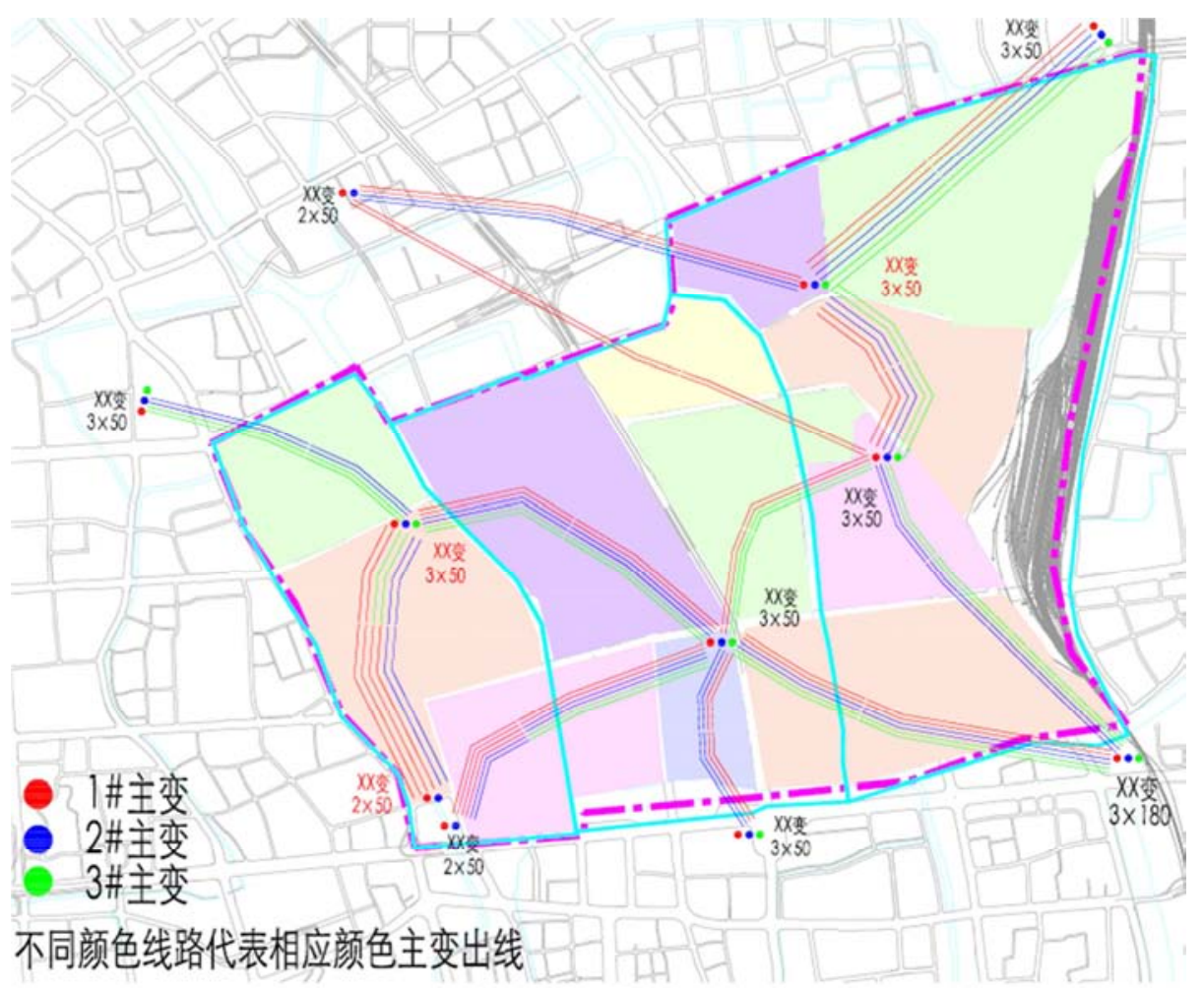

图16 规划区域主变组网示意图。

\section{4. 目标网架的构建}

中压线路沿街道布线结果如图17所示。至目标年, 规划区域所有供电网格主供线路明确, 网架结构合理, 联络关 系清晰; 中压线路联络率 $100 \%$, 均满足 N-1校验。

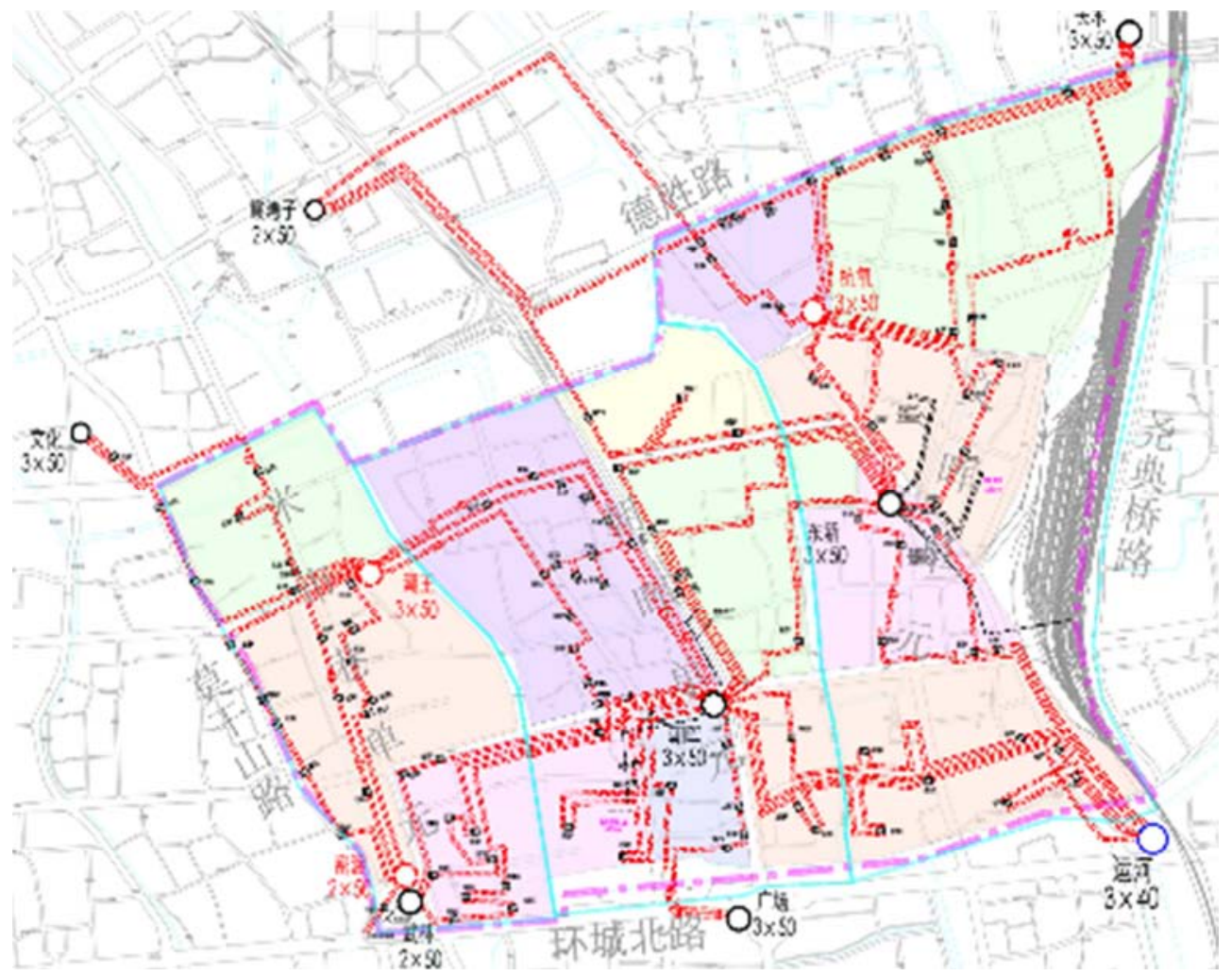

图17 规划区域10kV沿街道布线（红色虚线）。 


\section{5. 网架过渡方案}

2018年没有新建变电站投运，重点依据现状问题安排南部几个较成熟网格的建设改造项目；2019 2022年结合西 北部变电站新建逐步完善西北部网架, 2022 目标年结合东北部变电站新建逐步完善东北部网架。各网格在目标网架 建成之前, 依据实际需求, 以目标网架为约束, 重点解决重过载及不满足N-1等问题。
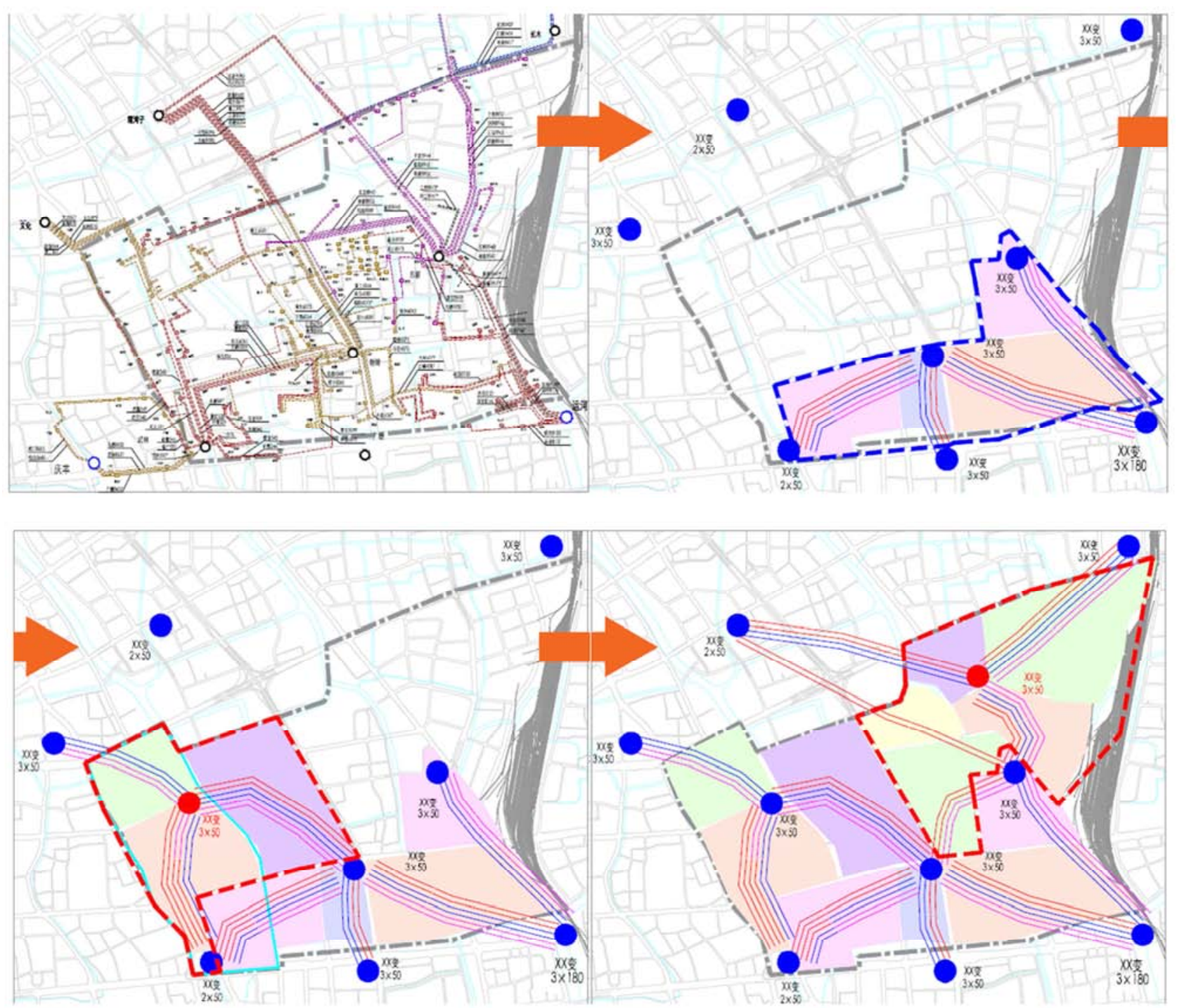

图18 网格逐年成片建设示意图（从左至右：现状年、2018年、2019年和2020年）

\section{8. 结论}

提出了一套完整的基于三层宏观组网约束的中压配 网精准规划方法, 主要结论有:

（1）三层宏观组网体现了全局统筹的顶层决定性和 网架的整体协调性: 通道组网优化和描绘了站间联络通道 的布局; 网格组网以成片组网的方式优化了网格划分; 主 变组网提高了全网主变设备的利用率。

（2）网格定义为以变电站为枢纽的负荷大小适中的 网孔型分区, 可分为站间联络网格和站内联络（或辐射型 接线）网格，各网格间相对独立; 网格组网或划分方法科 学规范, 结果趋于全局最优: 经济、可靠、唯一、差异和 精准。
（3）基于设备利用率提升和接线简洁的权衡，提出 了异站两主变间仅连两回为主的主变组网简单规则, 既能 兼容和完善现有导则, 又能适应电网的发展。

（4）针对新区、易改造地区和难改造地区过渡年网 架, 分别提出了新建一片成型一片、改造一片完善一片和 保持既有格局, 局部理清关系的具体应对措施。

（5）对空间上全局统筹、时间上远近结合和管理上 权责明确的理念从规划方法上提出了系统的落地方案, 全 面提升了网架和项目的科学性和唯一性, 体现了全局统筹 精准、方案过渡精准和管理职责精准。 


\section{参考文献}

[1] 张峰, 张建华. 基于网格化管理的城市中心区智能配电网 规划研究 [J]. 科技风, 2013(16)：230。

[2]国网浙江省电力公司经济技术研究院.配电网规划提升工 作标准体系（第二版）[R].国网浙江省电力公司, 2015。

[3] 杜敏.网格化一首都配网发展的新坐标[N].国家电网.2014 (128):100-102。

[4] 余建平.浦东核心区创建世界一流—配电网的初步构想 [J]. 电气应用，2013（2）:90-92。

[5] 姚刚, 仲立军, 张代.复杂城市配电网网格化供电组网方式 优化研究及实践 $[J]$. 电网技术, 2014, 38 (5)：1297-1301。

[6] 张植华, 李健, 林毓, 等.网格化城市配电网目标网架动态 构建方法 $[\mathrm{J}]$. 陕西电力，2015，43（2）：24-28。

[7] 李冬, 田强.中压配电网网格化规划方法研究[J]. 电工电气, 2014 (7) : 5-12。

[8] 刘瑞生.中低压配电网网格化规划探讨 [J]. 电工文摘, 2015: 40-43。

[9] 梁超友. $10 \mathrm{kV}$ 配电网“网格化”规划研究[J]. 山东工业技术,

[10] 张巧霞, 肖栋柱, 陆俭, 等.武汉城区配电网规划研究 [J]. 电力勘测设计，2013(05): 66-68。

[11] 霍凯龙, 王主丁, 畅刚.目标年中压配电网规划实用方法研 究 [J].电网技术，2013，06(2): 24-28。

[12] 吴涵, 林韩, 温步瀛, 等.巴黎、新加坡中压配电网供电模 型启示 $[\mathrm{J}]$. 电力与电工, $2010,31(2)$ : 4-7。

[13] 林韩, 陈涁, 吴涵, 等.面向远景目标网架的中压配电网供 电模型 $[\mathrm{J}]$. 电力系统及其自动化学报, 2011,23(6): 116-120。

[14] 乐欢, 王主丁, 吴建宾, 等. 中压馈线装接配变容量的探 讨 $[J]$. 华东电力, 2009，37（1）：586-588。

[15] 曹昉,孟琦斌,苗培青.基于改进加权Voronoi图和遗传算法的 变电站规划 $[J]$.电网技术,2015,39(2):511-516。

[16] QGDW1738-2012国家电网公司配电网规划设计技术导则 [S]．中华人民共和国国家电网公司，2006。

[17] Q/CSG-2016. 110 千伏及以下配电网规划技术指导原则 [S]．中国南方电网有限责任公司，2016。

[18] DLT5729-2016配电网规划设计技术导则[S], 中华人民共和 国电力行业标准, 中国电力企业联合会, 国家能源局, 2016。

[19] 马国栋.ISBN7-5083-1272-4电线电缆载流量 $[\mathrm{M}]$, 中国电力 出版社, 2003。 